\section{INCARCERATED RIGHT-SIDED DIAPHRAGMATIC HERNIA IN A PATIENT UNDERGOING ROUX-EN-Y GASTRIC BYPASS}

\author{
Daniel Navarini ${ }^{1,2,3}$, Paula da Rocha Jaskulski ${ }^{2}$, Diego Reffatti ${ }^{1,3}$, \\ Carlos Augusto Scussel Madalosso ${ }^{1,3}$, \\ André Emanuel Lunkes de Oliveira ${ }^{3}$, Fábio Roberto Barão ${ }^{1}$
}

\begin{abstract}
Bochdalek hernia is the most common congenital diaphragmatic hernia. Its symptoms are normally diagnosed and treated during the neonatal period. Conversely, in adults it is usually asymptomatic and, as a consequence, this group is misdiagnosed. A case of a 64-year-old female patient with an uncommon incarcerated right-sided diaphragmatic hernia formed three years after a Roux-en-Y gastric bypass and a significant weight loss is reported. The importance of this abnormality as a complication of the bariatric surgery should be considered.
\end{abstract}

Keywords: Diaphragmatic hernia; gastric bypass; bariatric surgery.

Most cases of diaphragmatic hernia occur during the neonatal period. The estimated incidence rate ranges from 1:2000 to 1:4000 live births $s^{1,2}$. This type of hernia results from a failure in the closure of pleuroperitoneal folds (responsible for the formation of diaphragm muscle) between the fifth and eighth weeks of pregnancy ${ }^{3}$. However, the etiopathogenesis of this disorder has not been completely clarified ${ }^{3}$.

The most usual location of this diaphragmatic defect is posterolateral, when it is called Bochdalek hernia $(\mathrm{BH})^{1,2}$. $\mathrm{BH}$ prevalence is considerably higher on the left side of the diaphragm, rarely affecting the right side ${ }^{1,3}$. Even though it is usually found in infancy, a small number of cases are diagnosed in adulthood ${ }^{1}$. Symptomatology in adults is uncommon, but, in some cases, there are vague manifestations and, even more rarely, acute intestinal obstruction ${ }^{4}$.

This is a report of a 64-year-old patient who had an important weight loss after undergoing Roux-en-Y gastric bypass and evolved with incarceration of the small intestine on the right diaphragm three years after surgery.

\section{CASE REPORT}

A64-year-old female patient was admitted to our department with a one-day history of intense and diffuse abdominal pain moderately relieved with opioid analgesics. She had undergone a laparoscopic Roux-en-Y gastric bypass three years earlier due to morbid obesity without other comorbidities. Physical examination revealed diffuse abdominal tenderness with no signs of peritoneal inflammation or any other abnormal finding. At admission, laboratory investigation showed normal results. Three-view acute abdominal series revealed the presence of bowel loops above the line of the diaphragm (Figure 1). The main hypothesis was that the patient was suffering from intestinal occlusion; thus, to elucidate the case, a laparoscopic surgery was indicated. The procedure showed jejunal loops adhered to the hepatic surface together with focal distention of the diaphragm. There was no alteration on the region of the gastric bypass and no other pathological findings were identified. 
Due to the impossibility of treating adhesions with a laparoscopic technique and with the suspicion of incarcerated diaphragmatic hernia, the procedure was changed to an open surgery (exploratory laparotomy). Multiple jejunal adhesions were identified on the right side of the diaphragm during the laparotomy, as well as on the hernial orifice (Figure 2A). Therefore, a diagnosis of diaphragmatic hernia with incarceration of the small intestine was confirmed.

After releasing these intestinal adhesions, we examined the viability of the loop of small intestine, which was well perfused without signs of ischemia (Figure 2B). Furthermore, the orifice found on the diaphragm muscle measured approximately $5 \mathrm{~cm}$ and was sutured with non-absorbable suture.

The patient had a satisfactory recovery and a chest radiography showed no abnormalities three days after the surgery. She was discharged from the hospital five days after the procedure.

\section{DISCUSSION}

Symptomatic Bochdalek hernia is common in neonates and can lead to life threatening cardiorespiratory emergency during this period, demanding immediate

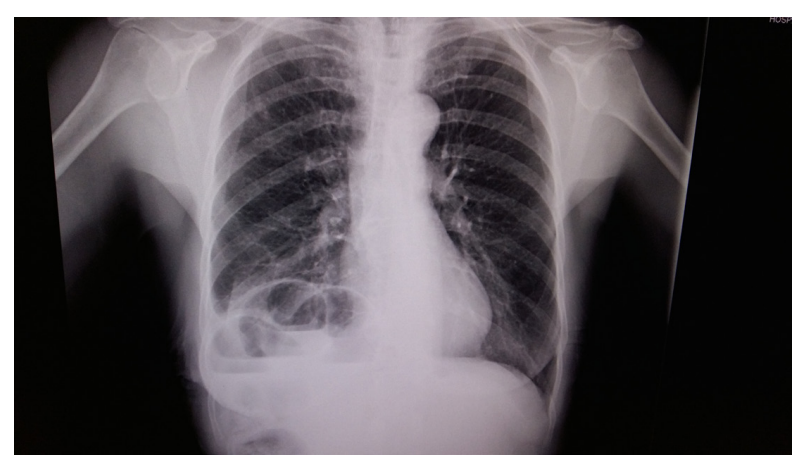

Figure 1: Chest radiography demonstrates the presence of bowel loops above the diaphragm line. diagnosis and management ${ }^{4}$. Conversely, congenital diaphragmatic hernia in adults is rarely diagnosed since only $25 \%$ of patients are symptomatic ${ }^{2}$. Hence, symptomatology in adults is uncommon, but symptoms may occasionally be present as nonspecific manifestations varying from chronic dyspnea to recurrent abdominal pain ${ }^{4}$. Furthermore, there is a rare possibility of $\mathrm{BH}$ being diagnosed from an abrupt onset of symptoms such as acute intestinal obstruction caused by visceral herniated incarceration or strangulation of different structures ${ }^{4}$.

A recent study analyzed 180 articles from 1955 to 2015 and reported 368 cases of $\mathrm{BH}$ in adults. It revealed that only 101 patients presented with right-sided diaphragmatic hernia ${ }^{5}$. A report from 2008 found 100 cases of $\mathrm{BH}$ described in the literature and among those there were 20 cases of right-sided hernia ${ }^{6}$. Some reports indicate that contents of left-sided hernias are usually colon, stomach, omentum, spleen, small bowel, pancreas and adrenal gland. Liver, gallbladder, kidneys and omentum are included in the contents of right-sided hernias ${ }^{7}$.

The formation of internal hernias after bariatric surgery is believed to be caused by a significant visceral fat loss, which is responsible for increased mobility of bowel and other intra-abdominal organs. Furthermore, as a consequence of the massive number of laparoscopic surgeries performed, less cases of postoperative abdominal adhesions have significantly contributed to improve organ mobility ${ }^{8}$.

Generally, lateral and frontal chest radiography can diagnose Bochdalek hernia. Images reveal whether bowel loops are filled with gas above the diaphragm or with soft tissue mass at the same topography. The sensitivity of chest radiography is low; thus, sometimes the diagnosis may not be clear. Therefore, a computed tomography (CT) or a magnetic resonance imaging (MRI) should be performed ${ }^{9}$.

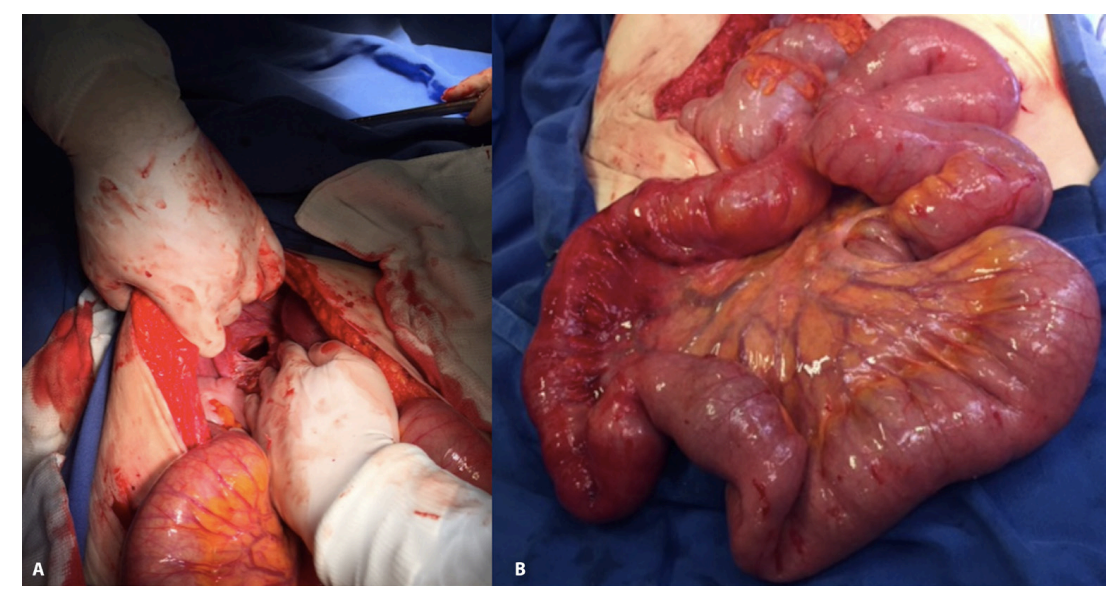

Figure 2: A - Diaphragm hernial orifice; B - Small intestine loops well perfused without signs of ischemia. 
The surgical approach to repair a diaphragm defect can be transthoracic or transabdominal, regardless of being a laparoscopy or an open surgery ${ }^{7,10}$. Transthoracic approach is preferred for right-sided $\mathrm{BH}$ because it facilitates the exposure of the diaphragm 6 . However, when there is suspicion of obstruction or strangulation, the transabdominal option with a midline incision should be considered ${ }^{6,7,10}$ in order to adequately evaluate visceral complications ${ }^{6}$. Regarding the closure of orifices, defects more than $5 \mathrm{~cm}$ in diameter should be repaired with tension-free mesh. Meanwhile, hernial orifice less than or equal to $5 \mathrm{~cm}$ in diameter can be repaired with primary closure with non-absorbable suture ${ }^{4}$.

\section{CONCLUSION}

Advances in bariatric laparoscopic surgery have enabled important visceral fat loss and have also decreased postoperative intestinal adhesions, raising mobility of intra-abdominal organs in this group of patients. Hence, this can be a reason for a significant incidence of internal hernias as a complication of this procedure. Bochdalek hernia is rarely found in adults because it is usually asymptomatic. However, as suggested by the case reported, $\mathrm{BH}$ incarceration may be triggered by this type of procedure, and a chest radiography is required for diagnosis. Finally, this rare and threatening condition should be included in the differential diagnosis among complications after bariatric surgery.

\section{REFERENCES}

1. Zhou Y, Du H, Che G. Giant congenital diaphragmatic hernia in an adult. $J$ Cardiothorac Surg. 2014;9(1):31. PMid:24512974. http://dx.doi. org/10.1186/1749-8090-9-31.

2. Laaksonen E, Silvasti S, Hakala T. Right-sided Bochdalek hernia in an adult: a case report. $J$ Med Case Reports. 2009;3(1):9291. PMid:20062780. http://dx.doi. org/10.1186/1752-1947-3-9291.

3. Bielinska M, Jay PY, Erlich JM, Mannisto S, Urban Z, Heikinheimo $\mathrm{M}$, et al. Molecular genetics of congenital diaphragmatic defects. Ann Med. 2007;39(4):261-74. PMid:17558598. http://dx.doi. org/10.1080/07853890701326883.

4. Kavanagh DO, Ryan RS, Waldron R. Acute dyspnoea due to an incarcerated right-sided Bochdalek's hernia. Acta Chir Belg. 2008;108(5):604-6. PMid:19051479. http://dx.doi.org/10.1080/00015458.20 08.11680298.

5. Machado NO. Laparoscopic repair of Bochdalek diaphragmatic hernia in adults. N Am J Med Sci. 2016;8(2):6574. PMid:27042603. http://dx.doi. org/10.4103/1947-2714.177292.

6. Oliveira DRCF, Rodrigues AJ JR. Hérnia de bochdalek em adulto. Rev Col Bras Cir. 2008;35(1):40-4. http://dx.doi.org/10.1590/S010069912008000100010.

7. Hung YH, Chien YH, Yan SL, Chen MF. Adult Bochdalek hernia with bowel incarceration. J Chin Med Assoc. 2008;71(10):528-31. PMid:18955188.
http://dx.doi.org/10.1016/S17264901(08)70162-X.

8. Mullan M, McFall B, McAllister I. Complications of gastric bypass surgery, a Northern Ireland experience. Ulster Med J. 2011;80(3):151-3. PMid:23526467.

9. Thomas S, Kapur B. Adult Bochdalek hernia: clinical features, management and results of treatment. Jpn J Surg. 1991;21(1):114-9. PMid:2041234. http://dx.doi.org/10.1007/BF02470876.

10. Shenoy KR, Johri G. Congenital right bochdalek hernia presenting as emergency in old age: a case report. Indian J Surg. 2013;75(S1 Suppl 1):255-6. PMid:24426583. http:// dx.doi.org/10.1007/s12262-012-05700 . 